\title{
Evaluating Clinical Ethics Support: On What Grounds Do We Make Judgments About Reports of Ethics Consultation?
}

\author{
Stella Reiter-Theil and Jan Schürmann
}

\section{Introduction}

In this chapter, we explore the question of on what grounds reports of clinical ethics support in general, including especially clinical ethics consultation, can or should be evaluated when using a peer review system, and we propose five core points to consider. It is our contention that to evaluate clinical ethics consultation within a peer review system aiming at transparency and fairness, one has to rely on defined and shared criteria of evaluation, i.e. an evaluation standard (although the term "standard" is by no means trivial, this chapter will not focus on its thorough clarification). Such a standard is grounded on a (defined and shared) conceptualization of how an ethics consultation should be performed. Obviously, there are different ways of doing clinical ethics consultation also corresponding with different evaluation standards (Pfaefflin et al. 2009; Schürmann et al. 2013). When evaluating a performed ethics consultation (according to a given documentation), we can roughly distinguish between an internal standard, which refers to the conceptualization of clinical ethics consultation held by the respective consultant or by the assessed clinical ethics support service (CESS) themselves, and external standards. Most important is the way how an external standard is being defined: Is it just the standard of another service or colleague? Or is it the result of a larger consensus-building process of a relevant body representing a larger group of colleagues such as the guidelines of the ASBH (2011)? Or does it even rely on the "evidence" of related research? An external standard, however, may rest on criteria that are not - or not fully accepted by the evaluated CESS or individual ethics consultant. However, identifying the internal standard of an observed ethics consultant's work may also be

\footnotetext{
S. Reiter-Theil ( $ه) \cdot J$. Schürmann

Department of Clinical Ethics, University Hospital Basel / University of Basel,

Basel, Switzerland

e-mail: s.reiter-theil@unibas.ch; jan.schuermann@unibas.ch
} 
challenging: Has it been published, and does it still apply to the recent case at hand? Is it clear or may there be misinterpretations? From the evaluator's perspective the responsibility for making an internal standard known and unequivocal lies with the "author" of the material. The potential gap between internal and external standards marks a methodological difficulty that as such has to be addressed within peer review evaluation.

Summarizing, we suggest that clinical ethics consultation should be evaluated by an internal standard held to be relevant by the respective consultant or CESS; moreover, we think that this internal standard must be in accordance with a general framework for the specific ethics consultation to be accessible to peer review evaluation. As a consequence of this coupled approach, the process of evaluation will avoid getting lost in a merely subjective, self-referential circle.

Besides different standards, there are also different kinds of methodological approaches to evaluate performed clinical ethics consultations, e.g. embedded research (Reiter-Theil 2012; Reiter-Theil and Schürmann 2016), analysis of (oral or written) reports, or analysis of videos. In analyzing oral or written reports, one can rely on different types of material such as case vignettes, records, narratives or feedback. Each type has different merits leading to specific strengths and weaknesses regarding the assessment, the data and conclusions. We suggest that an analysis relying on a combined report, including narrative and record, might best account for the weaknesses of each approach.

Finder's "The Zadeh Scenario" offers a rich narrative and in our eyes seems to implicitly communicate his internal standard of how to do clinical ethics consultation. He has, more importantly, made explicit his approach elsewhere - it may be described as a phenomenological-hermeneutical approach (Bliton and Finder 1999). In the first-level peer reviews given in this volume, the peer reviewers do not seem to embrace this approach in its full extension, as they assess Finder's narrative in "The Zadeh Scenario" using an approach that Bruce describes appropriately as "proceduralism" (Bruce 2018) - an approach that we consider, in this case, to be an external standard.

The type of report Finder has provided - a written narrative - is, according to our understanding, suitable to assess conversational, phenomenological, hermeneutical and existentialistic aspects of an ethics consultation. We think that Finder's narrative does well in addressing these aspects, with some shortcomings regarding the hermeneutical criterion. Considering further criteria of the proposed framework analytical, normative, interventional - "The Zadeh Scenario" falls short in providing the reader with a more comprehensive report and, especially, reflection.

\section{Critical Appraisal of the Commentaries}

Interestingly, each of the second-level commentaries (Part Three) achieve different things. Accordingly, in order to clarify their particular objectives, each must be addressed individually. 


\section{Bruce}

Bruce explores the methods referred to by the first-level reviewers to assess Finder's performance. Under "method" Bruce understands the systematic procedure, technique, or mode of inquiry employed during ethics consultation. Bruce presents four main methods discussed in clinical ethics literature: principlism, casuistry, narrative ethics, and clinical pragmatism. While the peer reviewers hardly refer to principlism and casuistry, they invoke several aspects of narrative ethics and clinical pragmatism. Regarding narrative ethics they refer to criteria such as engagement in dialogue, usage of open and well-crafted questions, involvement of all individuals concerned, or the richness of the story. Regarding clinical pragmatism, they refer to several procedural criteria: identifying the main ethical concern (of the requestor), clarifying the role of the ethics consultant, identifying and justifying appropriate treatment options, appealing to professional, legal or ethical standards, focusing on problem-solving, etc.

Bruce suggests that in using both narrative and procedural criteria the reviewers implicitly point to a new method which she calls "proceduralism." According to this approach, clinical ethics consultation should follow a systematic procedure that refers to the cited procedural criteria. It includes, however, as an additional procedural step any activities referring to the narrative criteria mentioned above. This, she argues, enables proceduralism to include the benefits of narrative ethics - discovery of meanings and values, context/case sensitivity, empathic support - and yet be effectively oriented at solving the ethical problem. Moreover it yields a distinct standard of procedural justification in ethics consultation: "Proceduralism allows for internal consistency and justificatory force to the extent that certain steps should be followed and justifications provided if these steps are not followed" (Bruce 2018: 123).

Bruce ends with four preliminary recommendations for clinical ethicists who get their ethics consultation assessed by peer review: (1) be explicit in your approach and justify deviations, (2) identify the nature of the ethical concern, (3) be explicit in your role, (4) identify and justify which interventions are considered inappropriate.

We tend to agree with Bruce's reconstruction of the method used by the firstlevel peer reviewers. However, it has to be acknowledged that proceduralism is an external standard that seems to deviate considerably from the internal standard used by Finder. Also, the reviewers' methodological conformity appears coincidental as several studies did indeed show the prevalence of principlism as method of ethics consultation (e.g. Slowther et al. 2012: 212). It would, thus, be at least somewhat premature to recommend the criteria of proceduralism as a kind of gold standard for peer review assessment.

Regarding Bruce's preliminary recommendations for reviewed clinical ethicists, it's not entirely clear whether these are meant to be "recommendations" referring to the doing of ethics consultation or referring to its documentation. As Rasmussen makes perfectly clear, these standards have to be distinguished and their relationship 
has to be clarified. We think that these recommendations capture important features that any kind of (oral or written) report has to display in order to be suited for peer review assessment.

\section{Aulisio}

The case narrative itself, rather than the first-level peer reviews, is further appreciated by Aulisio who raises a number of most interesting questions, e.g. on the role of the ethics consultant, the significance of autonomy- versus community-centric value sets, on hearing the voice of the patient, on the way of taking over a case from a colleague, on the request of a patient's family, to mention just a selection. Aulisio presents, instead of answering these questions, three "meta-methodological" lessons for method in clinical ethics consultation. They are as follows:

\section{Identifying and analyzing the underlying value conflict or uncertainties}

For Aulisio, the family's perception that they hold the value of "respecting and caring for parents" while suggesting that this was not the case in the surrounding majority U.S. culture, needs to be further explored so as to gain a broader understanding of the meaning of "respecting and caring for parents" as he - convincingly - supposes that the prevailing divergence might lie in the respective interpretations. Does "respecting and caring for parents" mean clinging to maximum life-supporting treatment, even given the evidence of burdening the patient with marginal expected benefit? Or could "respecting and caring for parents" also be understood as engaging in the search for the authentic wishes and needs of the patient, even if those may contradict the family's traditional customs or beliefs?

In his commentary (discussion of which is below), Agich criticizes Finder's approach when performing the ethics consultation arguing that he acted more like a "sensitive communicator and counselor for [the] family" (Agich 2018: 147). However, even in that role, one of the primary tasks would have been to clarify the values and commitments that were at stake in different possible interpretations. Aulisio's impression is that the expected value clarification did not take place (or was at least not provided in the narrative). Thus, rather than suggesting that Finder simply took on the role of another profession, the question must be asked, why did he act as he did, and on what grounds? More specifically, the question here is whether Finder's phenomenological framework of doing ethics consultation actually contributes to - or at least permits - a better understanding of the values and commitments (along with real or perceived conflicts and uncertainty) at stake?

\section{Clarifying who has the decision making authority}

Aulisio is quite adamant that all healthcare professionals, including ethics consultants, should maintain (or establish) respect for the authority of the patient in decision-making. He thus identifies as a "mistake" that the locus of decision-making appears to have been placed upon Mrs. Hamadani's family (instead of Mrs. 
Hamadani herself). Although this may be an unusually strong expression - in the sense that the talk of "mistakes" is still somewhat uncommon in clinical ethics literature (Rubin and Zoloft 2000) - it is the case that many nations (including our own home countries, Germany and Switzerland) have laws that reinforce ethical standards according to which, when patients lack capacity to participate in decisionmaking, healthcare professionals not ask patients' relatives or legal representatives for their own preferences regarding patient care; instead, they should be asked about the patient's values and preferences. Whatever else it is the role entails, therefore, it is an ethics consultant's task to ensure that this norm is followed. Against this frame, Aulisio also outlines a key role of the care team: to articulate the range of medically acceptable options and to offer clear recommendations. This includes, we would add, the task of articulating the limitations of interventions that do not make sense or create (moral) trouble such as the experience of practicing substandard pain control or futile care.

\section{Taking care that the patient's voice is being heard}

This serious concern of Aulisio's is illustrated by a label that is most telling: the "secondary patient." He warns us to prevent making "secondary patients" of family members with the risk of not only shifting the locus of decision-making but also the focus of care to the relatives rather than focusing on the patient. In explaining this challenge, Aulisio acknowledges the importance of nonetheless paying attention to the needs of the troubled family and making available relevant support from other appropriate professionals or resource groups. However, the question must be raised whether any limits or exceptions to the rule could be claimed from a moral perspective when the needs of a "secondary" patient (family member) have to be prioritized. For example, if a husband who promised to take care of his terminally ill, hospitalized wife is overburdened by this task and gets ill himself, his needs, as the "secondary patient," may indeed have to be prioritized over the wishes of the primary patient. This can be justified by the bridge principle "ought implies can": after falling ill, the husband has reached his limits and cannot maintain his promise to take care of his wife, and as a result, two primary patients emerge who both have needs and rights in themselves, even when they fall short of reciprocal wish-fulfilling.

We suppose that in Finder's case another option should be considered: some family members may have become a "primary patient" in their own right even if this is not explicitly communicated. According to "The Zadeh Scenario," this has not been an issue in the case. There is, however, another significant question: are there good reasons to suggest that Finder might have perceived such a critical situation within the Hamadani family? Did he perceive - without articulating - that some family members were in some kind of critical need situation where their "salvation," their moral or mental stability, required prioritized understanding or support because they otherwise might not have been able to escape "guilt" by consenting to palliative care goals?

On the whole, Aulisio's commentary is not only insightful and well supported by references, but also refreshing in his explicit questioning and constructive criticism. 
It is also appreciated that he explicitly addresses how an ethics consultant is dealing with the normative dimension of a case - and the related tasks in the role of being an ethics consultant. Aulisio doesn't further elaborate on the status of his "metamethodological" rules, apart from saying that they "are at a level of generality that makes them [...] compatible with and relevant for a wide variety of more specific models, approaches and methods of doing ethics consultation in health care settings" (Aulisio 2018: 128). We may account for this status by saying that these rules belong to a general framework describing what it means to do ethics consultation in the clinical context - a framework that is mandatory for peer review assessment of ethics consultation. Justifying such a status, however, cannot be done merely by exemplary case analysis, but requires conceptual analysis of both clinical and social norms as well as a robust consensus-building process among clinical ethics consultants.

\section{Agich}

In the first part of his chapter, Agich clarifies his understanding of doing clinical ethics consultation. In short, he understands ethics consultation essentially as a "reflective practice" in which the ethics consultant reflectively and responsibly engages in specific actions and communications such as gathering information, assessment, interpretation, planning meetings, analysis or providing advice. In doing so, the ethics consultant contributes to a hermeneutical process of giving meaning to the circumstances of the clinical case. This process builds on the conceptual, factual, evaluative and ethical views of the patient, family, and health care professionals involved, but also depends on a wider framework of social meanings. Agich considers three methodological implications of his reflective practice approach: (1) in order to define the distinctive set of rules guiding an ethics consultation, we have to neutrally describe the essential features of the doings in the practice of clinical ethics itself - and not, for instance, refer to ethical theory or methods; (2) the ability to enact these rules in practice is learned by way of actually performing and experiencing clinical ethics consultation - and not by studying formal codes, procedures, or guidelines; (3) in order to review an ethics consultation, we have to construe the whole "history" of that ethics consultation - not just look at its outcome. The history is ideally a set of critical reflections on all aspects of an ethics consultation which may be manifest in different kinds of reports (records, written or spoken narratives etc.).

In the second part, Agich focuses on four procedural features of Finder's performance: direct communication among ethics consultation team members, written ethics consultation records, the role of the ethics consultants, and the dynamic character of clinical ethics consultations. According to Agich, the direct communication between Finder and Moore was effective (which is essential). Similarly, Agich acknowledges the importance of having written records in the course of ethics consultation. In terms of the role of Finder, Agich is a bit more critical, briefly discussing 
that it seems to have been more that of a "sensitive communicator and counselor for [the] family" (Agich 2018: 147) than of an ethics consultant. As regards the dynamic character of clinical ethics consultation, Agich is again more positive, noting that this feature is admirably displayed by "The Zadeh Scenario." In the end, however, Agich questions the adequacy of Finder's narrative as a learning model for dealing with the normative dimension in ethics consultation.

In describing his reflective practice approach of clinical ethics consultation, Agich provides, according to our terminology, an external standard for evaluating Finder's ethics consultation. However, it remains unclear whether this evaluation standard is the same as the standard used by Finder or the first-level reviewers. We suppose that Agich's approach actually is quite similar to Finder's in its emphasis on engagement in a hermeneutical process with the individuals involved in a clinical case (for a description of Finder's approach, see our Discussion below). It lacks, in other words, a focus on referring to an explicit procedural framework - a statement that is paramount for the peer reviewers, as Bruce points out. Thus, in contrast to the first-level reviewers, Agich refers to an external standard that may count as internal as well. But this is only coincidental - we argue that for proper peer review assessment both internal and external standards, as well as their relationship, have to be articulated explicitly.

Agich's main criticism of "The Zadeh Scenario" is that it omits critical reflection of normative aspects of the case. This criticism is based on Agich's understanding of ethics consultation as a practice that primarily aims to provide thoughtful advice on ethical concerns rather than to provide emotional support for the patient's family. However, it remains unclear in what specific way Finder's performance misses the normative dimension, as Agich does not clarify how ethical concerns should be dealt with according to his own approach. In order to assess the handling of ethical concerns in the practice of clinical ethics by means of peer review assessment, examinee and reviewer have to agree on specific normative evaluation criteria.

The methodological implications Agich mentions also bear on peer review assessment. First, his insistence on the practical embeddedness of the rules guiding clinical ethics consultation reminds us that the evaluation criteria used in peer review have to be specified in view of the actual doings in ethics consultation. Second, in order to assess the whole "history" of clinical ethics consultation, we may have to rely on different kinds of material - not only narratives as in this case.

\section{Rasmussen}

Rasmussen's commentary starts by stating a number of limitations that arise for evaluation of ethics consultation when that evaluation is conducted by looking through the lens of the case narrative. Anticipating her clear, concise and constructive conclusion (we will come back to it in the Discussion), this recognition of such limitations reinforces the key message that the evaluation of ethics consultation requires standardization including a uniform standard for case reports 
themselves - which as she clarifies is distinct from a uniform standard for how a consultation is conducted.

As a kind of illustrative reason for the request for standardization, she explores the diversity of the five first-level peer reviewers in Part Two, with their "disparate targets" and nearly completely different ways of commenting on the case report, the result of which is "few commonalities, most notably with respect to procedure" (Rasmussen 2018: 153). One very basic divergence concerns the question raised in two out of the five peer reviews, namely whether "this is a clinical ethics consultation"; only one of the two confirms that this is the case.

In our view, possible triggers for this line of questioning are as follows:

(a) Finder's activity is different from an ethics consultation taking place "on demand", but appears (after the initial demand) to become increasingly selftriggered or -steered over time;

(b) it does not seem to focus on the needs of staff and it is not reported how ethical content matters are processed to the staff's benefit;

(c) although clinical ethics consultation can take place as a response to patient or family request, this does not seem to be the case here: rather, the family was simply asking Finder, in his administrative role as "Director," to remove the first ethics consultant;

(d) if an ethics consultation request is initiated from a staff need, but then shifts to focus on the needs and values of patient or family, some indication of the appropriateness of that shift is needed and must be included in the ethics consultation documentation; and finally,

(e) there seems to be a similarity between the at least partly non-requested involvement of the ethics consultant and the discussed risk of medical over-treatment.

What Rasmussen concludes (correctly, we believe) is that "this unsystematic approach accurately represents the state of the field" and "if case narratives are to be the coin of the new realm of attestation and quality improvement, systematicity in reporting is necessary" (Rasmussen 2018: 153). For further illustration, she picks two categories of observations: proceduralism and then feminist and multicultural issues.

With respect to proceduralism, Rasmussen notes that the authors in Part Two raise various procedural aspects of clinical ethics practice. There is, however, minimal overlap regarding questions about the (clarification of the) ethics consultant's role, similar to what we have discussed in the previous paragraphs in reference to Bruce, Aulisio, and Agich. Regarding feminism and multicultural issues, Rasmussen similarly states that the few responses to cultural elements (by three of the authors) "have next to no overlap" (Rasmussen 2018: 156). More importantly, however, Rasmussen explicitly draws attention to the fact that Armstrong seems to argue (Armstrong 2018: 69) that we should not assume that the patient would have wanted her family to make decisions for her because she is Persian (Rasmussen 2018: 156). Moreover, Rasmussen notes that Armstrong is also the only author who comments on a gender issue, observing that in "The Zadeh Scenario," Finder is calling the two daughters by their first names while calling their brother by his last name (as he does for the patient, always, and only, using "Mrs. Hamadani"). This 
observation is extended to stating that none of the female characters' opinions were explored. Interestingly, Aulisio did adjust this asymmetry by calling all three children of Mrs. Hamadani by their first names, including Samir, the son. However, this egalitarian approach did not extend to the healthcare (ethics) professionals who kept their last names throughout "The Zadeh Scenario" and the commentaries.

From an intercultural perspective we can point out a difference to some AngloAmerican practices. In a continental European culture, a non-reciprocal use of names would be most uncommon among adults (equals) and any deviation would be registered as surprising, especially in a professional context such as a hospital. A distinction exists in most European languages between addressing a person on familiar terms or in the formal form of address by using the personal pronouns of "Du" or "Sie", and it is a common practice, if not a social norm of good style, to respect mutuality (except for relations between, e.g., teachers and children). Thus, these observations seem to indicate that sensitive issues exist not only with regard to gender and communication, but also regarding the representative symbols of professional hierarchy towards patients and relatives.

In her reflections, Rasmussen articulates reservation about the assumption that clinical ethics practice could be evaluated by evaluating the retrospective case report - given the diversity of such reports. This leads to her conclusions that we are facing a double-layer problem: (1) a lack of standards regarding the individual ethics consultation and (2) the lack of standards regarding the ways they are documented. To adequately address these problems, Rasmussen suggests, requires not only standardizing the assessed elements of clinical ethics consultation as well as of clinical ethics consultation reports, but also promulgating these standards among all the participants of the assessment - otherwise, she says, peer review assessment will be "impossible, unfair, or arbitrary" (Rasmussen 2018: 159).

\section{Discussion}

The task to reflect methodologically on the peer reviews presented by the authors in Part Two is interpreted differently by each of the four authors in Part Three. This may not come as a surprise, as the concepts of method present a great deal of variety both in terms of theory and practice of clinical ethics consultation. Perhaps due to the difference in objective, there are hardly any open discrepancies between the commentaries in Part Three. One such discrepancy is the different emphasis Bruce and Rasmussen pursue when assessing the conformity among the Part Two reviews. Whereas Bruce suggests that they are similar enough to subsume them under the method of proceduralism, Rasmussen thinks that they hardly share the most basic assumptions - apart from the focus on procedure.

As to the task for Part Four, we acknowledge that each of the previous sets of reflections (Parts Two and Three) provides an opportunity to develop important conclusions about peer review assessment of clinical ethics consultation reports. We summarize these conclusions as follows. In peer review assessment of ethics consultation, (1) internal and external evaluation standards have to be articulated 


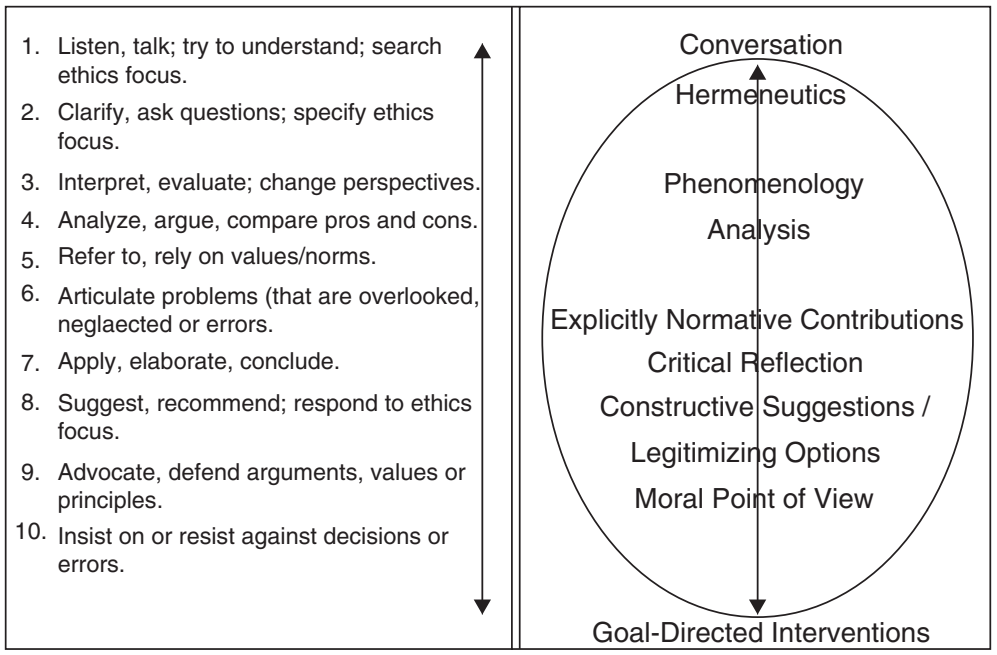

Fig. 1 Inventory and escalating model of dealing with the normative dimension in ethics consultation - the repertoire of an ethics consultant (Reiter-Theil (2009) with friendly permission by Cambridge University Press)

explicitly; (2) reviewee and reviewer have to agree on specific evaluation criteria applying to the actual doings in clinical ethics consultation; (3) these evaluation criteria should conform to a general evaluative framework; (4) that framework has to be validated in a consensus-building process among ethics consultants; (5) evaluation criteria are needed both for the doing of ethics consultation and for the documentation of ethics consultation; (6) the criteria regarding the doing of ethics consultation may require different kinds of material evidence than the criteria regarding the documentation of ethics consultation.

We rely on an integrative model (Reiter-Theil 2009) as a way of appreciating these suggestions and as a response to the demanding task to locate the divergent criteria of clinical ethics consultation that have emerged from the tableau of opinions into a conceptual framework. This model suggests a repertoire covering activities and approaches to be found in clinical ethics support (see Fig. 1). The underlying idea is that it makes sense to handle the normative dimensions of clinical encounters (i.e. ethical questions, conflicts, dilemmas) in an "escalation" approach. This strategy suggests that the low-level or "milder" activities are to be exhausted before engaging in higher-level and more directive interventions. In line with our proposal to apply both internal and external standards when evaluating ethics consultation material/activities of colleagues, using this model helps to distinguish between the criteria that are supposed to be shared by the ethics consultant(s) whose work is to be evaluated and those criteria that an observer wants to use as a measure (because such criteria seem to be founded on a large consensus - as in the case of the ASBH core competences). 
Finder's narrative in "The Zadeh Scenario" implicitly places his approach - as the authors in Parts Two and Three have vastly agreed - on the so-called "level of conversation with the family and the healthcare professionals," which seems to match the 1st level on Fig. 1; moreover, his approach does not seem to move to any higher level. No explicit clarification of values ( 2 nd level) has been carried out according to the narrative (as several authors have highlighted), nor has any interpretation (3rd level) or analysis (4th level) about the understanding of the value conflict and the options at stake been offered. We assume that these activities (at least levels 1-3, if not 4) would be part of a phenomenological-hermeneutical approach to ethics consultation. For verification of what may serve as Finder's internal standard, we need to look into the way Finder himself explicitly articulated his approach:

[W]e understand the main activity of ethics consultation as conducting conversations in [...] clinical situations in order to identify by speech, and through oneself as an example, what is most worthwhile to the participants in such conversations. We maintain, moreover, that the aim of clinical ethics consultation is to articulate and examine those possible meanings most prominently evoked within specific situations, which frequently involves identifying the problems perceived by those individuals confronted with a clinical decision, and entails gathering the viewpoints of many different participants included in that decision. All of which means that the method of ethics consultation must be clinical. In summary, clinical ethics consultation has two major characteristics. First, its activities are persistently guided by this question for the consultant, 'What do I need to know?' in order (a) to figure out why a clinical ethics consultation was requested? and (b) to get clear about 'what's going on?' Second, clinical ethics consultants seek to identify and discuss by persistently helping to elicit from the primary participants (patient, family, physicians, nurses, and so on) what they themselves find troubling and in need of resolution, and therefore what aftermaths they can live with in the light of what is most worthwhile to, and for, them. (Bliton and Finder 1999: 74-5, emphases in the original)

This description clearly shows Finder's conceptual insistence on the activities located on levels 1-3. It also highlights the perspective of the patient as a primary concern not only for problem resolution, but in the first place to understand the nature of the problem. If these activities are in accordance with an internal standard, reasons would be needed to explain why parts of this (phenomenologicalhermeneutical) clinical ethics repertoire were not used or not shown, e.g. value clarification. It is - we concede - possible that Finder did observe or conclude something that prevented him from following a path that would have appeared more stringent with his internal standard, but we do not see any hints for that in "The Zadeh Scenario," nor in the commentaries.

Using the referred to integrative model (Reiter-Theil 2009), however, does not imply that all levels have to be applied in all situations. The judgment about which steps are to be used has to be made in light of the context of the ethics consultation case. If as in this case the patient's voice appears to have gotten lost, it becomes a normative-ethical claim to make this voice audible, even in a situation of arising resistance (e.g., of the family)(see levels 6, 9 and 10). In some jurisdictions, adopting this claim is a matter of obeying the law and enacting existing ethical guidelines and principles, especially patient rights and respect for autonomy, and as such this normative basis requires the ethics consultant (but also the healthcare professionals) 
Table 1 Different evaluation methods and types of material in peer review assessment of EC

\begin{tabular}{l|l|l}
\hline Evaluation method & Types of material & Description (types of material) \\
\hline $\begin{array}{l}\text { Analysis of reports } \\
\text { oral or written) }\end{array}$ & Case vignette & $\begin{array}{l}\text { Short, summarizing description of an EC case } \\
\text { focusing on the medical situation, the ethical } \\
\text { problem and (possible) problem resolution }\end{array}$ \\
\hline & Record & $\begin{array}{l}\text { Record of an EC, written by a member of the } \\
\text { CESS }\end{array}$ \\
\hline & Narrative & $\begin{array}{l}\text { Detailed narrative of an EC case by a member } \\
\text { of the CESS focusing on the author's perspective }\end{array}$ \\
\hline Analysis of videos & Feedback & $\begin{array}{l}\text { Feedback of the patient, relatives or health care } \\
\text { providers of an EC }\end{array}$ \\
\hline Embedded research & $\begin{array}{l}\text { Observational data, } \\
\text { comprehensive report }\end{array}$ & $\begin{array}{l}\text { Life footage of an (actual or enacted) EC } \\
\text { structured information, field notes, diary }\end{array}$ \\
\hline
\end{tabular}

to work on the identified problem. We hold that this obligation is not even dependent on the (methodological) clinical ethics approach, but is a general duty. However, the style and the steps of how an ethics consultant would try to perform this task will and may vary - according to her approach. Finder, as the author of "The Zadeh Scenario," should (and we believe probably could) explain how he deliberately handled this normative issue. To prevent such gaps of assessment, it is important for the reviewed clinical ethics consultation service and the reviewers to agree in advance about the internal as well as the external standards that are to be utilized in evaluation.

On our review, most of the commentaries in Part Three and their critical reflections on method include the claim that activities corresponding with levels 2-8 in Fig. 1 are missing in "The Zadeh Scenario." We can imagine that several of the authors might even go as far as to request application of steps 9 or 10 in this case, e.g., for enacting the normative claim that the patient's voice and wishes must be made audible (e.g., Armstrong; Aulisio).

To our knowledge, there is no framework referring to different evaluation methods or types of materials used in peer reviewing clinical ethics consultation. A preliminary overview regarding methods and types of materials can be found in Table 1. We share Rasmussen's methodological reservations regarding the suitability of case narratives for peer review. In her thoughtful analysis she makes admirably clear that case narratives do require standardization in order to control for "idiosyncratic framing mechanisms" of their authors - and their readers as well and for the lack of crucial information. However, using a uniform standardization of case narratives might come with the loss of the specific advantages of narratives, namely to provide a first-person account of the situation. One solution, we suggest, consists in combining a narrative with a more formally structured record in order to compensate the shortcomings of narratives regarding procedural, analytical and normative criteria. 


\section{Conclusion}

Evaluation of clinical ethics support services - especially clinical ethics consultation - by peer review is an important task on the way towards improving the practice and developing related concepts.

We conclude by listing five core points to consider when evaluating ethics consultation:

- Peer review evaluation of clinical ethics consultation requires application of explicitly articulated external and internal standards both for the doing and for the documentation of ethics consultation. Different criteria may be required for the doing and for the documentation.

- Standardization of criteria is a prerequisite for the evaluation of ethics consultation. Also, the selection and structure of material(s) requested for evaluation should be explicitly standardized. Both requests have to be based on a professionwide discourse and consensus building as well as on an agreement between those carrying out the evaluation and those whose work is being evaluated.

- In order to balance the weight given to internal and external standards, the use of such standards in the evaluation of ethics consultation should be embedded within a wide, integrative model.

- General obligations - as articulated by law, professional standards, local mores, institutional orientations, communal normative guidelines and principles, and so forth - must be accounted for when establishing an evaluative set of criteria.

- The kinds of material evidence offered for clinical ethics consultation evaluation should be oriented to provide an authentic picture and to avoid gaps of significant information in order to accurately represent the relevant ethical issues of the case.

Acknowledgements We thank Professor Stuart Finder, $\mathrm{PhD}$, for his generous and trusting invitation to contribute to this project of evaluating a case of clinical ethics support. His courage could maybe should - become a milestone in developing this field further.

\section{References}

Agich GJ (2018) Narrative and method in ethics consultation. In: Finder SG, Bliton MJ (eds) Peer review, peer education, and modeling in the practice of clinical ethics consultation: the Zadeh project. Springer, Cham, pp 139-150

American Society for Bioethics and Humanities (2011) Core competencies for healthcare ethics consultation, 2nd edn. American Society for Bioethics and Humanities, Glenview

Armstrong K (2018) Telling about engagement is not enough: seeking the "ethics" of ethics consultation in clinical ethics case reports. In: Finder SG, Bliton MJ (eds) Peer review, peer education and modeling in the practice of clinical ethics consultation. Springer, Cham, pp 63-73

Aulisio MP (2018) (Meta-) methodological lessons for ethics consultation. In: Finder SG, Bliton MJ (eds) Peer review, peer education, and modeling in the practice of clinical ethics consultation: the Zadeh project. Springer, Cham, pp 127-137 
Bliton MJ, Finder SG (1999) The peculiar visage of philosophy in clinical ethics consultation. In: Zaner RM (ed) Performance, talk, reflection. What is going on in clinical ethics consultation? Kluwer Academic Publishers, Boston

Bruce CR (2018) Not principlism nor casuistry, not narrative ethics nor clinical pragmatism: a case for proceduralism. In: Finder SG, Bliton MJ (eds) Peer review, peer education, and modeling in the practice of clinical ethics consultation: the Zadeh project. Springer, Cham, pp 113-125

Pfaefflin M, Kobert K, Reiter-Theil S (2009) Evaluating clinical ethics consultation. Camb Q Healthc Ethics 18:406-419

Rasmussen L (2018) Standardizing the case narrative. In: Finder SG, Bliton MJ (eds) Peer review, peer education, and modeling in the practice of clinical ethics consultation: the Zadeh project. Springer, Cham, pp 151-160

Reiter-Theil S (2009) Dealing with the normative dimension in clinical ethics consultation. Camb Q Healthc Ethics 18:347-359

Reiter-Theil S (2012) What does empirical research contribute to medical ethics? a methodological discussion using exemplary studies. Camb Q Healthc Ethics 21:425-435

Reiter-Theil S, Schürmann J (2016) The 'big five' in 100 clinical ethics consultation cases. Evaluating three years of ethics support in the Basel University Hospitals. Bioethica Forum 9(2): $12-22$

Rubin SB, Zoloft L (eds) (2000) Margin of error. The ethics of mistakes in the practice of medicine. University Publishing, Hagerstown

Schürmann J, Mertz M, Reiter-Theil S (2013) "It is really about arguing?" why clinical ethics support needs metaethics. Unpublished. Poster presentation. International Conference on Clinical Ethics Consultation, March 14-16, 2013, Munich, Germany

Slowther AM, McClimans L, Price C (2012) Development of clinical ethics services in the UK: a national survey. J Med Ethics 38(4):210-214

Open Access This chapter is licensed under the terms of the Creative Commons Attribution 4.0 International License (http://creativecommons.org/licenses/by/4.0/), which permits use, sharing, adaptation, distribution and reproduction in any medium or format, as long as you give appropriate credit to the original author(s) and the source, provide a link to the Creative Commons license and indicate if changes were made.

The images or other third party material in this chapter are included in the chapter's Creative Commons license, unless indicated otherwise in a credit line to the material. If material is not included in the chapter's Creative Commons license and your intended use is not permitted by statutory regulation or exceeds the permitted use, you will need to obtain permission directly from the copyright holder.

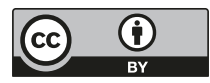

